Avian

Research

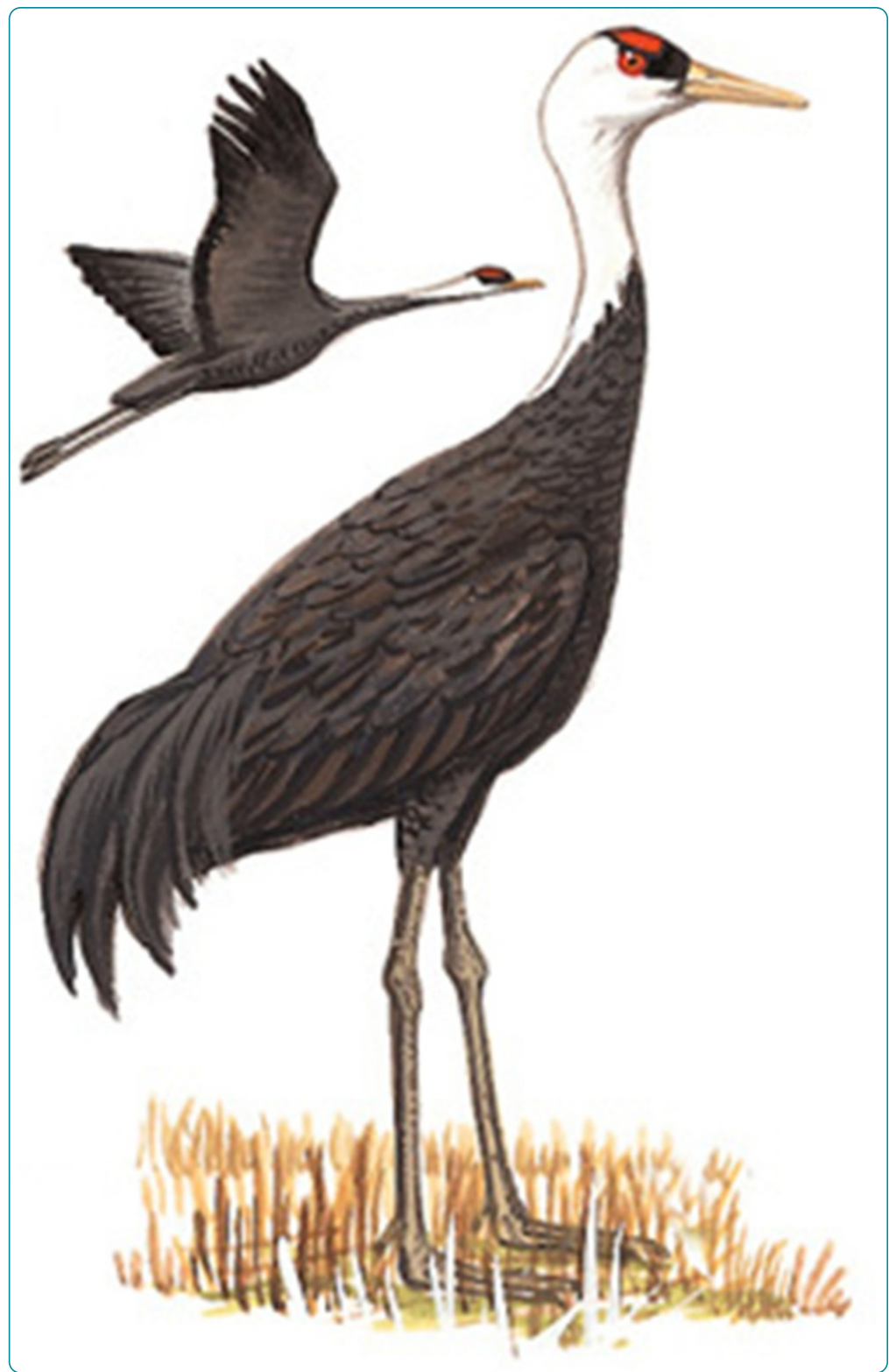

Temporal-spatial patterns of intestinal parasites of the Hooded Crane (Grus monacha) wintering in lakes of the middle and lower Yangtze River floodplain

Huang et al.

C Biomed Central 


\title{
Temporal-spatial patterns of intestinal parasites of the Hooded Crane (Grus monacha) wintering in lakes of the middle and lower Yangtze River floodplain
}

Wei Huang ${ }^{1,2}$, Lizhi Zhou ${ }^{1,2^{*}}$ and Niannian Zhao ${ }^{3}$

\begin{abstract}
Background: Parasites have adverse effects on the life and survival of many migratory waterbirds, especially birds on the endangered species list. Hooded Cranes are large migratory colonial waterbirds wintering in wetlands, which are prone to parasite infection, thus monitoring the diversity of parasites is important for sound wetland management and protection of this species.
\end{abstract}

Methods: From November 2012 to April 2013, we collected 821 fresh faecal samples from the three lakes (Poyang, Caizi and Shengjin Lake) in the lower and middle Yangtze River floodplain, and detected with saturated brine floating and centrifugal sedimentation methods. Parasite eggs were quantified with a modified McMaster's counting method.

Results: In this study, 11 species of parasites were discovered, i.e., two coccidium (Eimeria gruis, E. reichenowi), five nematodes (Capillaria sp., Strongyloides sp., Ascaridia sp., Trichostrongylus sp., Ancylostomatidae), three trematodes (Echinostoma sp., Echinochasmus sp., Fasciolopsis sp.) and one cestode (Hymenolepis sp.). About $57.7 \%$ of the faecal samples showed parasitic infection. All species of parasites were found at the three sites except Hymenolepis which was not found at Poyang Lake. While most samples were affected by only one or two species of parasites, infection by Eimeria spp. was the most common (53.1\%). From One-Way ANOVA analysis of the three lakes, parasite species richness index $(p=0.656)$, diversity index $(p=0.598)$ and evenness index $(p=0.612)$ showed no significant difference. According to the statistical analysis of our data, there were no significant difference in parasite species richness index $(p=0.678)$ and evenness index $(p=0.238)$ between wintering periods, but a strong difference in diversity index $(p<0.05)$.

Conclusions: Our study suggests that in the wintering Hooded Crane populations, parasite diversity is more sensitive to changes in the overwintering periods than to locations. This also indicates that with the limitations of migration distance, the parasites may not form the differentiation in Hooded Crane populations of the three lakes.

Keywords: Hooded Crane, Wintering population, Migratory waterbirds, Faecal parasite, Parasite diversity

\footnotetext{
* Correspondence: zhoulz@ahu.edu.cn

${ }^{1}$ Institute of Biodiversity and Wetland Ecology, School of Resources and Environmental Engineering, Anhui University, Hefei 230601, China

${ }^{2}$ Anhui Provincial Species Information Center, Hefei 230601, China

Full list of author information is available at the end of the article
} 


\section{Background}

Parasitic infection can result in an increase in mortality and a decrease in the birth rate of birds, thus regulating their population structure (Poulin et al. 2004; Marzal et al. 2005; Donovan et al. 2008; Traill et al. 2009; Hervías et al. 2013). Some authors are of the opinion that the effect of parasites on individual birds can affect the dynamics and sustainability of a bird population (Poulin 1999; Preston and Johnson 2010), thus functioning as a key component in conservation biology (May 1988). Several studies have gradually added avian parasites to the plethora of effects on seasonal change and the habitat of their hosts (Mellor and Rockwell 2006; Zamora-Vilchis et al. 2012; Woog et al. 2013). These studies provide insights into the ability of birds to cope with their natural, changing environment and their potential future reactions to environmental extremes. Migratory waterbirds should suffer more from parasites than other birds, due to their immunological suppression during migration and the high risk of infection in group living. Waterbirds in migration may encounter novel pathogens and, due to migratory pressures on the inhibition of their immunity, would be faced with a relapse of the disease that would otherwise have been limited to specific areas (Jourdain et al. 2007; Altizer et al. 2011). Group living means high population densities, where broad intraspecific crossing of parasite infections takes place (Dobson and Hudson 1986). Some rare species, like cranes, are an important focus for conservation efforts, while an understanding of the role that parasites play in wild populations will become vital for future conservation and management decisions. However, there is still a lack of baseline information about intestinal parasite infections for most crane species under natural conditions, which perhaps mainly due to sampling difficulties and a dearth of quantitative methods. The prevalence (percentage of infected individuals in a population) and infection intensity of parasites can provide some basic features of parasitic species (Poulin 1998; Poulin and Morand 2004), while richness, diversity and evenness are important measures of community structures of parasites (Poulin 1996; Marcogliese and Cone 1997). This provides an important clue to understanding the fitness and adaptive capacity of cranes to their parasites.

Hooded Cranes (Grus monacha) are large migratory colonial wading birds, breeding in south-central and south-eastern Siberia, Russia and winter in Japan, China and South Korea. An estimated 1050-1150 individuals overwinter in China, including between 300-400 at Poyang, more than 600 at Shengjin and Caizi and over 100 at Chongming (IUCN 2013). They generally arrive in late October and fly away in early April. They winter in freshwater marshes, wet grassland, coastal tidal flats and farmland. The roots and tubers of plants and rice, especially the tubers of hydrophytes, constitute the major food sources of Hooded Cranes, with small animals (e.g. earthworms, snails, mussels) also preferred sources of food. The population of this species is classified as Vulnerable on the IUCN Red List (IUCN 2013). As a way to cope with the lack of food and human disturbance, Hooded Cranes prefer to forage together in areas where food resources are relatively abundant (Zhou et al. 2010) and serve as an ideal research option for our study. The demography and behavior of the Hooded Crane has been studied extensively (Masatomi 2004; Zhou et al. 2010; Luo et al. 2012), yet information on infection by parasites, a factor increasingly acknowledged as an important ecological and evolutionary force, is very limited.

In our investigation, we largely focus on the parasitic diversity of wintering Hooded Crane populations to shed some light on the diversity of parasites, their intensity and spatial and temporal characteristics through fecal sample analyses. The aim was to determine: 1) the taxa of intestinal parasites occurring in these populations; 2) whether the parasites are homogeneously distributed in the three lakes; 3 ) the effect of various wintering areas and wintering periods on the diversity of parasites. Furthermore, some basic data are provided for the management and protection of the wintering population.

\section{Methods}

\section{Research areas}

Our research areas are the main wintering grounds of the Hooded Cranes in the lakes of the middle and lower Yangtze River floodplain, specifically Poyang Lake $\left(28.37^{\circ}-\right.$ $\left.29.75^{\circ} \mathrm{N}, 115.78^{\circ}-116.75^{\circ} \mathrm{E}\right)$, Shengjin Lake $\left(30.25^{\circ}-30.50^{\circ} \mathrm{N}\right.$, $\left.116.92^{\circ}-117.25^{\circ} \mathrm{E}\right)$ and Caizi Lake $\left(30.75^{\circ}-30.97^{\circ} \mathrm{N}, 117.00^{\circ}-\right.$ $117.15^{\circ} \mathrm{E}$ ) (Figure 1). All the three lakes are located in the northern subtropical monsoon climate zone, with an average annual temperature of $14-18^{\circ} \mathrm{C}$. Annual precipitation is $1000-1400 \mathrm{~mm}$, concentrated in the spring and summer seasons. The winter climate is cold and dry, with the occasional frost. The coldest month is January, with an average monthly temperature of $0-5.5^{\circ} \mathrm{C}$, while the lowest temperature during our study period was $-3^{\circ} \mathrm{C}$. The spring climate, however, is warm and moist, with an average monthly temperature of $10^{\circ} \mathrm{C}$. These three lakes are shallow, surrounded by mud flats, grass lands and paddy fields in winter and serve as stopovers and wintering sites for migratory waterbirds on the East Asian-Australian Flyway. The dry season usually lasts from December to February of the next year, with abundant food sources on the hydro-fluctuation belt exposed on the beaches. Seasonal changes in vegetation during the wintering period have an effect on the food sources available to Hooded Cranes, leading to changes in cluster size and group behavior. The three lakes are protected as natural reserves. 


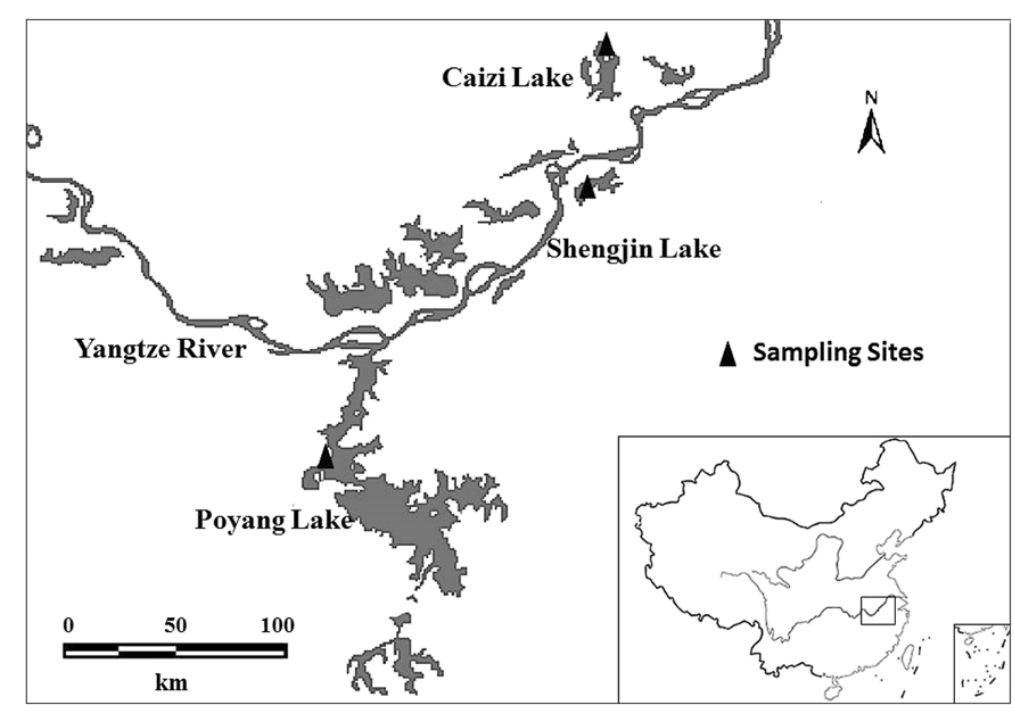

Figure 1 Sampling sites of faecal samples from wintering Hooded Cranes.

\section{Sample collection}

According to the migratory time of the cranes, the sampling times were divided into early (before February) and late wintering (after February) periods. From November 2012 to April 2013, a non-invasive sampling technique was used to collect the faeces of wintering crane populations from the three lake sites. Visits to each region were repeated three times during different sampling periods, once a week in turn. The foraging sites of Hooded Crane flocks were observed with a telescope before sampling, to ensure there were no flocks of other species. Only those flocks with more than 80 individuals were selected for sampling, and we collected 50 fresh fecal samples within each sampling period (Gregory and Blackburn 1991; Jovani and Tella 2006). To avoid individual sampling repetition, we collected samples with a minimum distance of at least $2 \mathrm{~m}$ (Zhang et al. 2012). Fresh faeces were collected in separate and clean plastic bags immediately after the cranes left and stored at $-20^{\circ} \mathrm{C}$ in our laboratory. To facilitate the analysis, samples of cranes from Poyang, Caizi and Shengin were abbreviated respectively as PY, $\mathrm{CZ}$ and SJ.

\section{Parasite inspection and enumeration}

Samples were processed using the modified flotation and sedimentation method (Wascher et al. 2012). Parasitic morphological identification was assessed by propagule size, shape, wall width and distinctive arrangement or identity of internal components. The preparation to enumerate was conducted with $1 \mathrm{~g}$ fresh faeces dissolved in a saturated saline solution (unit weight $1.195 \mathrm{~g} / \mathrm{L}$ ) in a $10 \mathrm{ml}$ centrifuge tube and centrifuged for $5 \mathrm{~min}$ at $3000 \mathrm{r} / \mathrm{min}$. The supernatant was transferred to a McMaster Egg Slide Counting Chamber and after three minutes the number of parasites was counted with 100 or 200 -fold amplification by checking the total number of eggs/oocysts on slides. For samples with a heavy parasite load, we performed preparation with another $1 \mathrm{~g}$ fecal sample, from where the supernatant was transferred into a conical flask with a constant volume to $60 \mathrm{~mL}$ with a saturated saline solution. This uniform mixture was then transferred to the McMaster Egg Slide Counting Chamber. The eggs/oocysts in the two counting rooms were counted; this count was multiplied by 200 which supplied the total number per $1 \mathrm{~g}$ of fecal sample (EPG/OPG). The sediment in the tube was conducted with filtration and centrifugal cleaning. The final residuum was a constant volume of $1 \mathrm{~mL}$, from which a $0.1 \mathrm{~mL}$ uniform mixture was used to check for trematodes. The final number was this quantity expanded ten times. Each count was repeated three times with a solution from the same operation. The results were recorded as number of eggs/oocysts per gram of feces for each parasite identified.

\section{Statistics}

We calculated the prevalence of all parasite species, i.e., the proportion of fecal samples in which we detected parasite propagules (eggs or oocysts). The intensity was measured by the number of eggs/oocysts per gram of fecal samples (EPG/OPG). Parasitic diversity was described by richness, diversity and evenness. Richness $(S)$ is defined as the total number of parasite species present in a fecal sample per site, where all levels of identifiable taxa were considered for species richness. Evenness $(J)$ is defined as a measure of disparity in the number of species identified in a collection (Bush et al. 1997) and diversity $\left(H^{\prime}\right)$ is the composition of a parasite community in terms of the number of species present (Bush et al. 1997). 
Prevalence:

$P=$ number of positive samples/number of all samples tested (\%) at each sampling site;

$P_{i}=$ number of specific parasite propagules/number of all parasite propagules in sample tests of a collection.

Shannon-Wiener index:

$$
H^{\prime}=-\sum_{i=1}^{S} P_{i}\left(\ln P_{i}\right)
$$

Maximum diversity index:

$$
H_{\max }=\ln S
$$

Evenness index:

$$
J=H^{\prime} / H_{\max }
$$

Our data were classified according to their sampling areas and collection periods. For parasitic contrasts among the three lakes, the data were listed as separate collections with a different order of sampling. For the comparison between wintering periods, the data were listed as the total collection of the three lakes with the same sampling order and sampling periods. Chi-square and Fisher's exact tests were carried out to determine the statistical significance of differences in proportions of parasitic fauna between wintering periods. Parasite richness, diversity and evenness were compared among groups of different lakes by One-Way ANOVA and then between groups of different sampling periods. The IBM
SPSS Statistics v19.0 was used for statistical analyses. Statistical significance was assumed at $p<0.05$.

\section{Results}

Parasite community structure and prevalence

Eleven parasites were observed from 821 fecal samples of Hooded Cranes from our research areas, i.e., Eimeria gruis (32.6\%), E. reichenowi (41.8\%), Capillaria sp. (3.7\%), Strongyloides sp. (4.1\%), Ascaridia sp. (6.1\%), Trichostrongylus sp. (2.3\%), Ancylostomatidae (2.6\%), Echinostoma sp. (2.1\%), Echinochasmus sp. (1.6\%), Fasciolopsis sp. (1.1\%) and Hymenolepis sp. $(0.4 \%)$. About $57.7 \%(n=474)$ of faecal samples showed parasitic infection. All of the 11 species of parasites were present in the three regions, except for the Hymenolepis sp. which was not found at Poyang Lake. Eimeria was the most common species with the highest infection rate, i.e., 53.1\%. The prevalence of protozoa, nematodes and trematodes detected in PY was higher than that in SJ and CZ (Table 1).

A significant difference was found in the prevalence between early and late wintering periods (Table 2). The prevalence of protozoa, nematodes and trematodes was higher at the late wintering sites except that of trematodes at CZ. Coccidia and nematode prevalence in late winter was significantly higher than that in early winter, while the prevalence of trematodes and cestodes in late winter was smaller than that in early winter. Significant differences were found in the infection rates of both protozoa $\left(\chi^{2}=32.174, \mathrm{df}=1, p<0.05\right)$ and nematodes $\left(\chi^{2}=6.012, \mathrm{df}=1, \quad p<0.05\right)$, while no significant

\begin{tabular}{|c|c|c|c|c|c|c|c|c|}
\hline \multirow[t]{2}{*}{ Taxon } & \multicolumn{2}{|c|}{ PY $(N=204)$} & \multicolumn{2}{|c|}{$C Z(N=312)$} & \multicolumn{2}{|l|}{ SJ $(N=305)$} & \multicolumn{2}{|c|}{ Total $(N=821)$} \\
\hline & Frequency & Prevalence (\%) & Frequency & Prevalence (\%) & Frequency & Prevalence (\%) & Frequency & Prevalence (\%) \\
\hline PROTOZOAN & 125 & 61.3 & 172 & 55.1 & 139 & 45.6 & 436 & 53.1 \\
\hline Eimeria gruis & 71 & 34.8 & 98 & 31.4 & 99 & 32.5 & 268 & 32.6 \\
\hline Eimeria reichenowi & 104 & 51.0 & 122 & 39.1 & 117 & 38.4 & 343 & 41.8 \\
\hline NEMATODE & 40 & 19.6 & 47 & 15.1 & 52 & 17.0 & 139 & 16.9 \\
\hline Capillaria sp. & 15 & 7.4 & 9 & 2.9 & 6 & 2.0 & 30 & 3.7 \\
\hline Strongyloides sp. & 5 & 2.5 & 16 & 5.1 & 13 & 4.3 & 34 & 4.1 \\
\hline Ascaridia sp. & 8 & 3.9 & 18 & 5.8 & 24 & 7.9 & 50 & 6.1 \\
\hline Trichostrongylus sp. & 2 & 1.0 & 6 & 1.9 & 11 & 3.6 & 19 & 2.3 \\
\hline Ancylostomatidae & 12 & 5.9 & 5 & 1.6 & 4 & 1.3 & 21 & 2.6 \\
\hline TREMATODE & 14 & 6.9 & 11 & 3.5 & 14 & 4.6 & 39 & 4.8 \\
\hline Echinostoma sp. & 4 & 2.0 & 7 & 2.2 & 6 & 2.0 & 17 & 2.1 \\
\hline Echinochasmus sp. & 4 & 2.0 & 3 & 1.0 & 6 & 2.0 & 13 & 1.6 \\
\hline Fasciolopsis sp. & 6 & 2.9 & 1 & 0.3 & 2 & 0.7 & 9 & 1.1 \\
\hline CESTODE & 0 & 0 & 2 & 0.6 & 1 & 0.3 & 3 & 0.4 \\
\hline Hymenolepis sp. & 0 & 0 & 2 & 0.6 & 1 & 0.3 & 3 & 0.4 \\
\hline
\end{tabular}

Table 1 Distribution of parasites collected for Grus monacha from three lakes in the middle and lower Yangtze River floodplain, China, 2012-2013 
Table 2 Specific composition of parasites between sampling periods

\begin{tabular}{|c|c|c|c|c|}
\hline \multirow[t]{2}{*}{ Taxon } & \multicolumn{2}{|c|}{ Number of infected samples } & \multicolumn{2}{|c|}{ Test statistics } \\
\hline & $\begin{array}{l}\text { Early wintering } \\
(N=404)\end{array}$ & $\begin{array}{l}\text { Late wintering } \\
(N=417)\end{array}$ & $x^{2}$ & $p^{a}$ \\
\hline Protozoan & 174 & 262 & 32.174 & $0.000^{*}$ \\
\hline Nematode & 32 & 55 & 6.012 & $0.014^{*}$ \\
\hline Trematode & 20 & 19 & 0.070 & 0.791 \\
\hline Cestode & 3 & 0 & - & $0.119^{b}$ \\
\hline
\end{tabular}

${ }^{\mathrm{a} D i f f e r e n c e ~ i n ~ p r e v a l e n c e ~ o f ~ p a r a s i t e ~ f a u n a ~ o f ~ t w o ~ s a m p l i n g ~ p e r i o d s ~ u s i n g ~}$ Pearson's chi-square test.

${ }^{\mathrm{b}}$ Analyzed with Fisher's exact test.

${ }^{*} p<0.05$.

differences were found in these rates in trematodes $\left(\chi^{2}=0.070, \mathrm{df}=1, p=0.791\right)$ and cestodes $(p=0.119)$.

\section{Parasite distribution in the three lakes}

Considerable differences were found in the infection intensity among parasite species (Table 3). The most abundant species were coccidian oocysts $(41.8 \%$ for $E$. reichenowi and $32.6 \%$ for E. gruis), followed by Ascaridia sp. (13.9\%), Strongyloides sp. (5.4\%), Capillaria sp. (3.3\%) and Ancylostomatidae (1.6\%). E. reichenowi dominated while Fasciolopsis sp. made a rare appearance. Trematodes occupied a smaller percentage of the total number, with lower intensity compared to nematodes and coccidium. Species with the highest infection intensity do not, as a rule, mean the largest abundance. Despite the differences in the number of species, the distributions of species dominance in the three lakes were nearly the same.

Most positive samples contained one or two species of parasites. Uninfected samples accounted for 29.9\% $(n=61$, 95\% CI: $23.6-36.2 \%)$ in PY, $45.5 \%$ ( $n=142$, 95\% CI: $40.0-$
51.0\%) in CZ and 47.2\% ( $n=144,95 \%$ CI: 41.6-52.8\%) in SJ. Samples with a single species of parasites were more common than those containing two or more. Their prevalence at PY was higher than that at CZ and SJ, where it was similar. Samples containing three or more species were significantly smaller in number in all parasitic fauna. Less than $1 \%$ of the samples contained four species (Figure 2).

\section{Parasitic diversity}

In decreasing order of parasitic diversity and evenness, the following order prevailed: $\mathrm{PY}>\mathrm{SJ}>\mathrm{CZ}$ (Table 4). Although Hymenolepis sp. was not detected at PY $(S=10$, $N=204)$, there was no significant difference in species richness (ANOVA, $F_{2,15}=0.666, p=0.656$ ) among the three lakes. No significant differences were detected in parasitic diversity $\left(F_{2,15}=0.756, p=0.598\right)$ and evenness $\left(F_{2,15}=0.733, p=0.612\right)$ among the three lakes. The maximum diversity index was 1.436 at PY. Parasitic evenness indices were $0.624,0.571$ and 0.582 for PY, CZ and SJ, respectively. In general, parasitic diversity and evenness of the Hooded Cranes at the three lakes were similar.

During the two sampling periods, we observed variation in the parasitic diversity and evenness indices (Table 5). In the two sampling periods, the parasitic richness index was not significant different $\left(F_{1,4}=0.200, p=0.678\right)$, while the diversity index was higher in the late wintering period than during early wintering and showed significant statistical difference $\left(F_{1,4}=12.317, p<0.05\right)$. Though some changes were observed in evenness, there was no significant statistical difference $\left(F_{1,4}=1.925, p=0.238\right)$. The highest parasitic diversity index $\left(H^{\prime}=1.571\right)$ was observed in late wintering, while the lowest $\left(H^{\prime}=1.340\right)$ occurred during early wintering.

Table 3 Median intensity and range of parasitic propagules (oocysts or eggs) detected in sample tests of faeces from 821 Hooded Cranes from the three lakes (OPG/EPG)

\begin{tabular}{|c|c|c|c|c|c|c|c|}
\hline \multirow[t]{2}{*}{ Taxon } & \multicolumn{2}{|l|}{ PY } & \multicolumn{2}{|l|}{$\mathrm{CZ}$} & \multicolumn{2}{|l|}{ SJ } & \multirow{2}{*}{$\begin{array}{l}\text { Total percentage } \\
\text { (\%) }\end{array}$} \\
\hline & Median & Range & Median & Range & Median & Range & \\
\hline Eimeria gruis & 233 & $7-2700$ & 200 & $2-4300$ & 250 & $5-5500$ & 32.6 \\
\hline E. reichenowi & 467 & $4-3200$ & 233 & $3-8200$ & 267 & $3-7600$ & 41.8 \\
\hline Capillaria sp. & 150 & $39-767$ & 73 & $24-467$ & 75 & $12-800$ & 3.3 \\
\hline Strongyloides sp. & 75 & $10-1200$ & 200 & $13-733$ & 167 & $22-1000$ & 5.4 \\
\hline Ascaridia sp. & 250 & $35-3733$ & 70 & $2-1400$ & 217 & $18-2100$ & 13.9 \\
\hline Trichostrongylus sp. & 40 & 34,46 & 34 & $4-300$ & 51 & $13-400$ & 1.0 \\
\hline Ancylostomatidae & 100 & $28-467$ & 41 & $19-233$ & 70 & $22-400$ & 1.6 \\
\hline Echinostoma sp. & 15 & $10-47$ & 23 & $10-70$ & 20 & $10-50$ & 0.2 \\
\hline Echinochasmus sp. & 13 & $3-40$ & 10 & $7-27$ & 20 & $10-43$ & 0.1 \\
\hline Fasciolopsis sp. & 7 & $3-20$ & 10 & 10 & 12 & 3,20 & 0.1 \\
\hline Hymenolepis sp. & 0 & 0 & 66 & 26,105 & 43 & 43 & 0.1 \\
\hline
\end{tabular}




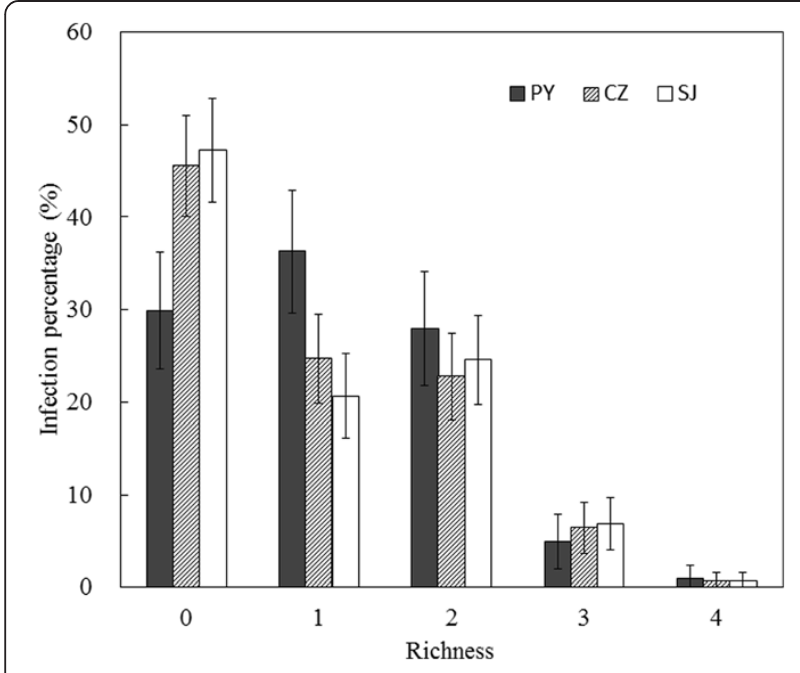

Figure 2 Proportion of various species richness detected in fecal samples. PY: Poyang Lake; CZ: Caizi Lake; SJ: Shengjin Lake.

\section{Discussion}

\section{Characteristics of parasitic infection}

Parasitic infection levels in Hooded Cranes seem to be low compared with previous reports on intestinal parasites of free-range Eurasian Cranes (Grus grus) (78.9\%, $N=728$ ) (Fanke et al. 2011). The most common parasite was coccidia $(53.1 \%, n=436)$, followed by Ascaridia sp. $(6.1 \%, n=50)$, Strongyloides sp. $(4.1 \%, n=34)$ and Capillaria sp. $(3.7 \%, n=30)$. Possible interpretation is that all species of parasites mentioned were newly discovered in the wild Hooded Cranes, with the exception of Eimeria coccidian.

It was reported that at least seven species of wild cranes can be infected by Eimeria coccidia at high frequencies (Honma et al. 2011), causing serious injury or death to young birds (Novilla and Carpenter 2004; Spalding et al. 2009). High population densities are believed to increase the risk of infection (Honma et al. 2011). The incidence of Eimeria coccidia infection in our investigation was clearly lower than that reported for the Hooded Cranes wintering in Japan, which is most likely due to a lower host density. Nematodes are also an important part of the intestinal parasitic community, a lethal factor for migratory cranes (Varela et al. 2001; Mowlavi et al. 2006; Fanke et al. 2011). Ascaridia sp.,
Strongyloides sp. and Capillaria sp. observed in our study have been reported earlier in other wild cranes (Gaines et al. 1984; Spalding et al. 1996), while infection can lead to anemia, weakness and other diseases to many waterbirds. Porrocaecum sp. (Forreste et al. 1974) and Contracaecum sp. (Spalding et al. 1996) also have been reported earlier in cranes but have not been detected in Hooded Cranes. Echinostoma sp. is a species of trematodes accounting for $2.1 \%$ in our research; it sucks blood from many waterbirds (Ballweber 2004). Most parasites have low prevalence and positive samples could be found only within short periods. This is probably the reason why wild Hooded Cranes do not often show significant disease characteristics. Parasitic infection and environmental pressures often lead to host weakness, weight loss or even death (Mowlavi et al. 2006). Cranes with a heavy parasitic burden suffer considerably from adverse conditions, such as disease, predators, hunger and other negative factors (Novilla and Carpenter 2004), which makes them vulnerable.

\section{Temporal and spatial variation of prevalence and diversity}

Prevalence among parasitic communities (protozoa, nematodes, trematodes, cestodes) is relatively similar, suggesting that the community structure of the parasites is stable. Eimeria and nematodes are the most common species, probably because of their direct life cycles, while lower levels of trematode and cestode infections may be due to an indirect life history (Rausch 1983). From the results of this study, we found that the prevalence of parasites was higher in the Poyang population, suggesting that it is more prone to infection.

The similarity of parasitic communities tends to have a negative correlation with geographical distance and environmental conditions (Poulin et al. 2011). Whether a single ecological factor determines the uniformity of a particular host-parasite community is not clear. Parasitic species and prevalence varied among the three lakes, but the richness, diversity and evenness indices did not show significant statistical differences over the spatial divide. Similar diversity and evenness indicates that most of these parasitic species occur in these three lakes, with some species present at high levels.

Prevalence of Hooded Crane parasites in the late wintering period was significantly higher than that in the

Table 4 Diversity indices of parasites at different sampling sites

\begin{tabular}{|c|c|c|c|c|c|}
\hline Index & PY $(N=204)$ & $C Z(N=312)$ & SJ $(N=305)$ & $F$ & $p$ \\
\hline Species richness $(S)$ & 10 & 11 & 11 & 0.666 & 0.656 \\
\hline Shannon-Wiener Index $\left(H^{\prime}\right)$ & 1.436 & 1.369 & 1.395 & 0.756 & 0.598 \\
\hline Pielou Index ( () & 0.624 & 0.571 & 0.582 & 0.733 & 0.612 \\
\hline
\end{tabular}


Table 5 Diversity indices of parasites between sampling periods

\begin{tabular}{|c|c|c|c|c|c|c|c|c|}
\hline \multirow[t]{2}{*}{ Index } & \multicolumn{3}{|c|}{ Early wintering } & \multicolumn{3}{|l|}{ Late wintering } & \multicolumn{2}{|c|}{ Statistics test } \\
\hline & $\begin{array}{l}\text { 1st sampling } \\
(N=136)\end{array}$ & $\begin{array}{l}\text { 2nd sampling } \\
(N=130)\end{array}$ & $\begin{array}{l}\text { 3rd sampling } \\
(N=138)\end{array}$ & $\begin{array}{l}\text { 1st sampling } \\
(N=134)\end{array}$ & $\begin{array}{l}\text { 2nd sampling } \\
(N=144)\end{array}$ & $\begin{array}{l}\text { 3rd sampling } \\
(N=139)\end{array}$ & $F$ & $p$ \\
\hline Species richness $(S)$ & 8 & 10 & 10 & 10 & 9 & 10 & 0.200 & 0.678 \\
\hline Shannon-Wiener Index $\left(H^{\prime}\right)$ & 1.436 & 1.340 & 1.362 & 1.571 & 1.474 & 1.518 & 12.317 & $0.025^{*}$ \\
\hline Pielou Index ( () & 0.691 & 0.582 & 0.591 & 0.682 & 0.671 & 0.659 & 1.925 & 0.238 \\
\hline
\end{tabular}

${ }^{*} p<0.05$.

early period. A significant difference was found between the prevalence of protozoa and nematodes. The consistency of results found in the three parasitic fauna is not a coincidence. Parasitic diversity of the wintering Hooded Cranes in the late wintering period was substantially higher than that in the early wintering period. This suggests that parasitic diversity is more sensitive to the wintering period than to location.

\section{Reasons for differences in parasitic diversity}

Earlier investigations, for example in the case of the Eurasian Crane, have also reported variation in parasitic infection in different seasons and migratory paths (Gottschalk and Prange 2001). The results may have many explanations. In the first place, the intestinal parasitic community could be altered by migration dynamics. Studies have shown that bird migration is likely to be an escape strategy in response to heavy concentrations of parasites due to excessive use of habitats (Altizer et al. 2011; Møller and Szép 2011). Before migration habitats are excessively used, and this increases the risk of parasitic infection (Mellor and Rockwell 2006). Parasite pressure may be relieved during migration. In addition, different arrival times of the Hooded Cranes also affect the abundance of parasites (Figuerola et al. 2000). For example, in our sampling period, early-arriving cranes lost a large number of parasitic species from the breeding sites, while cranes which joined late may have preserved them. Secondly, parasitic infection is subjected to environmental effects (Pietrock and Marcogliese 2003). For parasites where eggs are deposited in faeces, temperature, rainfall and humidity can affect both rates of parasitic development and the survival of external stages (Altizer et al. 2006). Eggs or oocysts ingestion appeared to be the most common mode of infection in our study. The infectious stages for intestinal parasites are vulnerable to variation in temperature and humidity (Calegaro-Marques and Amato 2013). The climate in the early wintering period is cold and dry and parasitic eggs will not easily survive, leading to a reduction in infection. In the late wintering period, however, there are many moist and warm shelters and parasites may then have developed a strong capacity for infection due to favorable habitat factors. Furthermore, ecological factors such as habitat use or the availability of other resources of their hosts may affect the composition of these parasite clusters (Esch et al. 1990). When resources, including food, are exhausted in late wintering periods, the Hooded Cranes gather in lager flock size more often at paddy fields and later transferred to grasslands for limited food resources (Zhou et al. 2010). Faecal contamination may increase parasitism by increasing host susceptibility or by increasing the abundance of intermediate hosts and vectors (Lafferty 1999). Oocysts or eggs exposed to repeatedly used habitats could easily be ingested, leading to a significant rise in prevalence and diversity. In contrast to free ranging birds always living in a limited range, wild Hooded Cranes would freely choose preferred habitats during some periods, which reduces outbreak of diseases and keeps their population healthy.

Habitat disturbance could lead to disease outbreaks by creating suitable conditions for individual species (Dobson and May 1986) and the Hooded Cranes in wetlands are prone to human disturbance. Thus, monitoring the diversity of parasites is important for sound wetland management. Intestinal parasites in the wild Hooded Cranes in our present research are only roughly portrayed and further research is needed to gain more information about parasites. Although fecal flotation technique will underestimate the true prevalence and might miss the rare parasite, we believe that this approach remains accurate in revealing the infection regularity of parasites in the Hooded Cranes (Wagner et al. 2012).

\section{Conclusion}

Our study suggests that in the wintering Hooded Cranes populations, parasite diversity is more sensitive to changes in the overwintering periods than to locations. Given the similarity of parasitic community structures in the three lakes and the limitations related to Hooded Crane migration, our results also suggest that the parasites may fail to be isolated due to geographical factors. Molecular genetic analyses in future research may better reveal this phenomenon. 


\section{Competing interests}

The authors declare that they have no competing interests.

\section{Authors' contributions}

LZ, WH and NZ designed the experiments, and WH conducted the experiments. $\mathrm{WH}$ and $\mathrm{LZ}$ analyzed the data and finished the earlier draft of the manuscript. LZ and NZ contacted nature reserve authorities and got permission for fieldwork. All authors read and approved the final manuscript.

\section{Acknowledgments}

This study was supported by the National Natural Science Foundation of China (31172117) and the Graduate Student Innovation Research Projects of Anhui University (YQH100611). We gratefully acknowledge the assistance of Dr. Chunlin Li and Dr. Gang Liu for their comments on the manuscript. We also thank Professor Peiying Li for her help in parasite identification.

\section{Author details}

${ }^{1}$ Institute of Biodiversity and Wetland Ecology, School of Resources and Environmental Engineering, Anhui University, Hefei 230601, China. ${ }^{2}$ Anhui Provincial Species Information Center, Hefei 230601, China. ${ }^{3}$ Anhui Shengjin Lake National Nature Reserve, Dongzhi 247200, China.

\section{Received: 5 August 2014 Accepted: 9 August 2014}

\section{Published online: 20 October 2014}

\section{References}

Altizer S, Dobson A, Hosseini P, Hudson P, Pascual M, Rohani P (2006) Seasonality and the dynamics of infectious diseases. Ecol Lett 9:467-484

Altizer S, Bartel R, Han BA (2011) Animal migration and infectious disease risk. Science 331:296-302

Ballweber LR (2004) Waterfowl parasites. Semin Avian Exot Pet 13:197-205

BirdLife International (2013) Grus monacha. In: IUCN 2013. IUCN Red List of Threatened Species. Version 2013.2, Http://www.iucnredlist.org

Bush AO, Lafferty KD, Lotz JM, Shostak AW (1997) Parasitology meets ecology on its own terms: Margolis et al. revisited. J Parasitol 83:575-583

Calegaro-Marques C, Amato SB (2013) Seasonal influences on parasite community structure of Turdus rufiventris (Aves). J Parasitol 99:1-5

Dobson AP, Hudson PJ (1986) Parasites, disease and the structure of ecological communities. Trends Ecol Evol 1:11-15

Dobson AP, May RM (1986) Patterns of invasions by pathogens and parasites. In: Mooney HA, Drake JA (eds) Ecology of Biological Invasions of North America and Hawaii. Springer Verlag, New York, pp 58-77

Donovan TA, Schrenzel M, Tucker TA, Pessier AP, Stalis IH (2008) Hepatic hemorrhage, hemocoelom, and sudden death due to Haemoproteus infection in passerine birds: eleven cases. J Vet Diagn Invest 20:304-313

Esch GW, Shostak AW, Marcogliese DJ, Goater TM (1990) Patterns and processes in helminth parasite communities: an overview. In: Esch GW, Bush AO, Aho JM (eds) Parasite Communities: Patterns and Processes. Chapman and Hall, London, pp 1-19

Fanke J, Wibbelt G, Krone O (2011) Mortality factors and diseases in free-ranging Eurasian cranes (Grus grus) in Germany. J Wildl Dis 47:627-637

Figuerola J, Green AJ (2000) Haematozoan parasites and migratory behaviour in waterfowl. Evol Ecol 14:143-153

Forreste DJ, Bush AO, Williams LE, Weiner DJ (1974) Parasites of greater sandhill cranes (Grus canadensis tabida) on their wintering grounds in Florida. Proc Helminthol Soc Washington 41:55-59

Gaines GD, Warren RJ, Pence DB (1984) Helminth fauna of sandhill crane populations in Texas. J Wildl Dis 20:207-211

Gottschalk C, Prange H (2001) Parasites of the common crane Grus grus (L.) in Europe. Berl Munch Tierarztl Wochenschr 115:203-206

Gregory RD, Blackburn TM (1991) Parasite prevalence and host sample size. Parasitol Today 7:316-318

Hervías S, Ramos JA, Nogales M, Ruiz DYR (2013) Effect of exotic mammalian predators on parasites of Cory's shearwater: ecological effect on population health and breeding success. Parasitol Res $112: 2721-2730$

Honma H, Suyama Y, Watanabe Y, Matsumoto F, Nakai Y (2011) Accurate analysis of prevalence of coccidiosis in individually identified wild cranes in inhabiting and migrating populations in Japan. Environ Microbiol 13:2876-2887

Jourdain E, Gauthier-Clerc M, Bicout D, Sabatier P (2007) Bird migration routes and risk for pathogen dispersion into western Mediterranean wetlands. Emerg Infect Dis 13:365-372

Jovani R, Tella JL (2006) Parasite prevalence and sample size: misconceptions and solutions. Trends Parasitol 22:214-218

Lafferty KD, Kuris AM (1999) How environmental stress affects the impacts of parasites. Limnol Oceanogr 44:925-931

Luo J, Wang Y, Yang F, Liu Z (2012) Effects of human disturbance on the Hooded Crane (Grus monacha) at stopover sites in northeastern China. Chinese Birds 3:206-216

Marcogliese DJ, Cone DK (1997) Parasite communities as indicators of ecosystem stress. Parassitologia 39:227-232

Marzal A, De Lope F, Navarro C, Møller AP (2005) Malarial parasites decrease reproductive success: an experimental study in a passerine bird. Oecologia 142:541-545

Masatomi H (2004) Individual (non-social) behavioral acts of Hooded Cranes (Grus monacha) wintering in Izumi, Japan. J Ethol 22:69-83

May RM (1988) Conservation and disease. Conserv Biol 2:28-30

Mellor AA, Rockwell RF (2006) Habitat shifts and parasite loads of lesser snow geese (Chen caerulescens caerulescens). Ecoscience 13:497-502

Møller AP, Szép T (2011) The role of parasites in ecology and evolution of migration and migratory connectivity. J Ornithol 152:141-150

Mowlavi GR, Massoud J, Mobedi I, Gharagozlou MJ, Rezaian M, SolaymaniMohammadi S (2006) Tetrameres (Tetrameres) grusi (Shumakovich, 1946) (Nematoda: Tetrameridae) in Eurasian Cranes (Grus grus) in Central Iran. J Wildl Dis 42:397-401

Novilla MN, Carpenter JW (2004) Pathology and pathogenesis of disseminated visceral coccidiosis in cranes. Avian Pathol 33:275-280

Pietrock M, Marcogliese DJ (2003) Free-living endohelminth stages: at the mercy of environmental conditions. Trends Parasitol 19:293-299

Poulin R (1996) Patterns in the evenness of gastrointestinal helminth communities. Int J Parasitol 26:181-186

Poulin R (1998) Comparison of three estimators of species richness in parasite component communities. J Parasitol 84:485-490

Poulin R (1999) The functional importance of parasites in animal communities: many roles at many levels? Int J Parasitol 29:903-914

Poulin R, Morand S (2004) Parasite Biodiversity. Smithsonian Books, Washington

Poulin R, Blanar CA, Thieltges D, Marcogliese DJ (2011) The biogeography of parasitism in sticklebacks: distance, habitat differences and the similarity in parasite occurrence and abundance. Ecography 34:540-551

Preston D, Johnson P (2010) Ecological consequences of parasitism. Nat Educ Knowl 1:39

Rausch RL (1983) The biology of avian parasites: helminths. Avian Biol 7:367-442

Spalding MG, Kinsella JM, Nesbitt SA, Folk MJ, Foster GW (1996) Helminth and arthropod parasites of experimentally introduced whooping cranes in Florida. J Wildl Dis 32:44-50

Spalding MG, Carpenter JW, Novilla MN (2009) Disseminated visceral coccidiosis in cranes. In: Atkinson CT, Thomas NJ, Hunter DB (eds) Parasitic Diseases of Wild Birds. Wiley-Blackwell, New Jersey, pp 181-194

Traill LW, Bradshaw CJ, Field HE, Brook B (2009) Climate change enhances the potential impact of infectious disease and harvest on tropical waterfowl. Biotropica 41:414-423

Varela A, Kinsella JM, Spalding MG (2001) Presence of encysted immature nematodes in a released whooping crane (Grus americana). J Zoo Wildl Med 32:523-525

Wagner BA, Hoberg EP, Somers CM, Soos C, Fenton H, Jenkins EJ (2012) Gastrointestinal helminth parasites of Double-crested Cormorants (Phalacrocorax auritus) at four sites in saskatchewan, Canada. Comp Parasitol 79:275-282

Wascher CA, Bauer AC, Holtmann AR, Kotrschal K (2012) Environmental and social factors affecting the excretion of intestinal parasite eggs in graylag geese. Behav Ecol 23:1276-1283

Woog F, Maierhofer J, Haag H (2013) Endoparasites in the annual cycle of feral Greylag Geese Anser anser. Wildfowl 61:166-181

Zamora-Vilchis I, Williams SE, Johnson CN (2012) Environmental temperature affects prevalence of blood parasites of birds on an elevation gradient: implications for disease in a warming climate. PLoS One 7:e39208 
Zhang L, Zhou L, Dai Y (2012) Genetic structure of wintering Hooded Crane (Grus monacha) based on mitochondrial DNA D-loop sequences. Chin Birds 3:71-81

Zhou B, Zhou L, Chen J, Cheng Y, Xu W (2010) Diurnal time-activity budgets of wintering Hooded Cranes (Grus monacha) in Shengjin Lake, China. Waterbirds 33:110-115

doi:10.1186/s40657-014-0006-6

Cite this article as: Huang et al.: Temporal-spatial patterns of intestinal parasites of the Hooded Crane (Grus monacha) wintering in lakes of the middle and lower Yangtze River floodplain. Avian Research 2014 5:6.

\section{Submit your next manuscript to BioMed Central} and take full advantage of:

- Convenient online submission

- Thorough peer review

- No space constraints or color figure charges

- Immediate publication on acceptance

- Inclusion in PubMed, CAS, Scopus and Google Scholar

- Research which is freely available for redistribution 